\title{
AVALIAÇÃO E REGISTRO NO CURRÍCULO CULTURAL DA EDUCAÇÃO FÍSICA
}

ARTHUR MÜLLER'

MARCOS GARCIA NEIRA"

Universidade de São Paulo (USP), São Paulo-SP, Brasil; educacaofisica_arthur@yahoo.com.br

II Universidade de São Paulo (USP), São Paulo-SP, Brasil: mgneira@usp.br

\section{RESUMO}

A avaliação abarca um dos temas mais controversos e polêmicos dentro do sistema educacional. De acordo com a atitude curricular, essa prática adquire os mais variados contornos, podendo assumir desde um caráter classificatório e excludente, até um caráter investigativo ou analítico. Adotar esse segundo viés implica o desprendimento da quantificação, da atribuição de valores para aprendizagens ditas bem-sucedidas e a classificação dos estudantes. 0 presente artigo tem como objetivo analisar a função que o registro adquire no currículo cultural da Educação Física. Para tanto, submetemos ao escrutínio documentação pedagógica elaborada por um professor que atua em uma escola estadual paulista, analisando como reorganiza suas ações didáticas de acordo com os registros das atividades de ensino e das respostas dos estudantes. Os resultados evidenciam o potencial do registro como recurso para a avaliação do trabalho realizado e a consequente reorientação da rota.

PALAVRAS-CHAVE EDUCAÇÃo FíSICA • AVALIAÇÃo • CURRÍCULO CULTURAL・REGISTRO. 


\section{EVALUACIÓN Y REGISTRO EN EL CURRÍCULO CULTURAL DE LA EDUCACIÓN FÍSICA \\ RESUMEN}

La evaluación abarca uno de los temas más controvertidos y polémicos dentro del sistema educativo. Según la actitud curricular, esta práctica adquiere los más variados contornos y puede asumir desde un carácter clasificatorio y excluyente hasta un carácter investigativo o analítico. Adoptar este segundo sesgo implica el desprendimiento de la cuantificación, de la atribución de valores para aprendizajes considerados exitosos y la clasificación de los estudiantes. El presente artículo tiene el objetivo de analizar la función que o registro adquiere en el currículo cultural de la Educación Física. Para ello, sometemos al escrutinio documentación pedagógica elaborada por un profesor que actúa en una escuela estadual de São Paulo, analizando cómo reorganiza sus acciones didácticas de acuerdo con los registros de las actividades de enseñanza y de las respuestas de los estudiantes. Los resultados ponen de manifiesto el potencial del registro como recurso para la evaluación del trabajo realizado y la consecuente reorientación de la ruta.

PALABRAS CLAVE EDUCACIÓN FÍSICA • EVALUACIÓN • CURRÍCULO CULTURAL • REGISTRO.

\section{EVALUATION AND DOCUMENTATION IN THE CULTURAL CURRICULUM OF PHYSICAL EDUCATION}

ABSTRACT

Evaluation covers one of the most controversial issues within the educational system. According to the curriculum in action, this practice acquires the most varied contours, assuming either a classificatory and excluding character or an investigative and analytical character. Adopting the latter implies disregarding quantification and the assignment of values for successful learning, as well as the classification of students. The purpose of this article is to analyze the function that the documentation acquires in the cultural curriculum of Physical Education. Thus, we scrutinized pedagogic documentation prepared by a teacher who works in a public school in São Paulo state, analyzing how didactic actions are reorganized according to the records of teaching activities and student responses. The results show the potential of documents as a resource for the evaluation of the work performed and the consequent reorientation of the route.

KEYWORDS PHYSICAL EDUCATION • EVALUATION • CULTURAL CURRICULUM • DOCUMENTATION. 


\section{A ROTA DOCENTE: O CURRÍCULO CULTURAL}

$O$ esforço que a sociedade brasileira tem empreendido nas últimas décadas vem transformando a escola, de um espaço exclusivo para determinados grupos, em um ambiente favorável ao ingresso e permanência de todos. A consequência é o constante choque entre culturas de chegada e aquelas historicamente privilegiadas no currículo. Nesse sentido, o termo "tolerância", tão comum no trato com as diferenças, tem sido paulatinamente substituído nos documentos e textos educacionais por "valorização", o que vai além da simples verificação e compreensão das culturas.

Trata-se de considerar aspectos culturais, sociais e histó-

ricos, tornando possível, assim, a compreensão da colocação em destaque ou não das várias culturas que integram o ambiente escolar e seu entorno. E mais, trata-se de compreender e analisar quais os mecanismos que permitem que certas culturas gozem de certo prestígio social, deixando tantas outras de lado, atribuindo-Ihes um caráter marginalizado e calando as vozes de seus representantes. (MÜLLER, 2016, p. 47) 
Uma proposta de Educação Física pautada nesses pressupostos, aqui denominada "currículo cultural" ou "culturalmente orientado", requer o diálogo com práticas mais solidárias, contribuindo para que os sujeitos da educação reconheçam os saberes dos grupos minoritários, alinhando-se às lutas que têm empreendido pelo direito à representação. É nesse contexto que a negociação cultural ganha força no combate à imposição e homogeneização. Afinal, o ponto medular tem que ser a resistência à opressão, ao preconceito e à discriminação, com o objetivo de construir uma sociedade menos desigual.

Uma educação para a negociação cultural, que enfrenta
os conflitos provocados pela assimetria do poder entre os
diferentes grupos socioculturais nas nossas sociedades e
é capaz de favorecer a construção de um projeto comum,
pelo qual as diferenças sejam dialeticamente incluídas.
(CANDAU, 2008, p. 23)

Conceitualmente, o multiculturalismo crítico, o pós-estruturalismo, o pós-colonialismo e os estudos culturais constituem-se em campos teóricos que inspiram intervenções pedagógicas a favor das diferenças (NEIRA, 2018). Enquanto o primeiro e o segundo nos auxiliam a compreender os discursos que atravessam as relações sociais, hierarquizando saberes e práticas, o terceiro e quarto concebem a cultura como um terreno em que os significados atribuídos às coisas do mundo decorrem de disputas assimétricas por validação e legitimação.

Hall (1997) explica que o resultado desse emaranhado cultural pode não ser a substituição de algo "velho" pelo "novo", mas a criação de híbridos, como ocorre nas sociedades multiculturais. Pensando no contexto escolar, uma única visão não é capaz de abarcar todos os estudantes. É por isso que a ação dialógica proporciona novos caminhos a partir do choque entre diferentes representações circundantes do ambiente escolar.

No currículo cultural da Educação Física as aulas passam

a ter como objetivo contribuir para a leitura dos signos presentes nas práticas corporais, bem como na produção 
de novas manifestações corporais. Não se trabalha apenas

a ação motora, mas amplia-se o estudo para os significados que os diferentes grupos dão às práticas. Ou seja, por meio desta proposta os sujeitos da educação vão, constantemente, ampliando seu repertório cultural ao acessarem alguns códigos de comunicação de outras culturas. (SANTOS, 2016, p. 40)

O professor que atua a partir do currículo cultural é influenciado por princípios ético-políticos que ganham materialidade em atividades de ensino específicas. Neira (2011) aponta: 1) "o reconhecimento das identidades culturais dos estudantes" com intuito de valorizar as raízes da comunidade na qual a escola está inserida, o que faz com que as práticas corporais dos grupos de origem e pertencimento dos alunos transformem-se em temas de estudo; 2) a "justiça curricular" se refere ao esforço para equilibrar o tratamento das brincadeiras, danças, lutas, esportes e ginásticas oriundos dos vários grupos que coabitam a sociedade contemporânea, com intuito de proporcionar condições para expressão e audição de várias vozes, sem que se privilegiem determinados conhecimentos, discursos e práticas em detrimento de outros; 3) a "descolonização do currículo" é a tematização de práticas corporais dos grupos subalternizados e que têm estado ausentes do currículo. Esse princípio permite aos alunos perceberem como as narrativas subordinadas são silenciadas enquanto as práticas culturais hegemônicas narram o outro colonizado como objeto de curiosidade; 4) "evitar o daltonismo cultural" implica considerar a heterogeneidade presente em todas as salas de aula e, por consequência, as respostas distintas às mesmas atividades e a necessidade de adoção de dispositivos de diferenciação pedagógica; e 5) "ancoragem social dos conhecimentos" requer que se tome, como ponto de partida, a ocorrência social das práticas corporais, e que seu lastro histórico e político seja devidamente analisado.

Investigando a prática pedagógica do currículo cultural, Bonetto (2016) percebeu que os princípios são tomados pelos docentes para definição das práticas corporais a serem 
tematizadas e organização das atividades de ensino. Essas, por sua vez, abarcam: 1) o "mapeamento" do universo cultural corporal da comunidade, ocasião em que o docente reúne, por meio de observações e conversas, informações acerca das produções discursivas e não discursivas referentes às práticas corporais acessadas pelos estudantes; 2) "leitura das práticas corporais", momento em que a ocorrência social da manifestação tematizada é submetida à análise; 3) "vivências/ressignificações" são os momentos em que o formato conhecido das brincadeiras, danças, lutas, esportes e ginásticas é experimentado e reconstruído de forma coletiva; 4) "aprofundamento" congrega as atividades que se voltam para um conhecimento mais detalhado da prática corporal; 5) "ampliação" requisita o acesso a outros pontos de vista sobre o tema em tela, logo, o acesso a representações ainda não disponíveis aos estudantes; 6) o "registro e avaliação" são indissociáveis, pois é a documentação da trajetória percorrida que permitirá o exame detalhado do processo e as considerações sobre seus efeitos no alunado. Registrar é dar sentido às atividades de ensino realizadas por meio da retomada e reflexão sobre o que aconteceu na aula, as falas e os silêncios.

Santos (2016) denominou "tematização" o conjunto das atividades de ensino que caracterizam o currículo cultural da Educação Física. Assim organizadas, as situações didáticas proporcionam aos estudantes vários focos de análise da prática corporal objeto de estudo. O autor também identificou que a ligação entre elas se dá por meio da "problematização" das representações anunciadas pela turma durante as aulas. Problematizando os discursos que envolvem as práticas corporais e seus representantes, o docente viabiliza a "desconstrução" das representações opressoras, hegemônicas, discriminatórias, misóginas e homofóbicas, dentre outras tantas.

Vistas em sintonia, a tematização, a problematização e a desconstrução conferem imprevisibilidade aos conteúdos, pois, segundo Bonetto (2016), é justamente o caráter aberto da proposta que possibilita, a cada docente, a reorganização do encontro didático de amanhã, conforme as respostas apresentadas pelos estudantes às experiências promovidas 
1 Para seus registros, professor utilizou a ferramenta EverNote. Trata-se de um aplicativo que pode ser baixado em smartphone ou tablet que permite várias formas de registros: fotos, vídeos e áudio com voz. Assim, é possível que, durante as aulas, o docente grave sua própria voz com suas observações acerca daquilo que está analisando, enquanto as crianças realizam a aula de Educação Física. Ainda sobre o Caderno de Registro. vale ressaltar que esse se constituiu em um material empírico de documentação e consulta exclusivo do docente. Conforme orientação da direção da escola, as informações contidas podem ser socializadas. As fotos/vídeos não foram, em qualquer momento da escrita divulgados, preservando, dessa forma, a identidade das crianças. hoje. A tal plasticidade, que toma como base a condição de autoria do professor, o autor denominou "escrita-currículo". Em certo sentido, o conceito de escrita-currículo explica a maneira como o currículo cultural da Educação Física ganha vida nas escolas, ou seja, dá continuidade ao trabalho de Santos (2016). Embora os estudos citados tenham mencionado a avaliação, não aprofundaram a discussão, tampouco analisaram o papel que o registro ocupa na materialização da proposta.

\section{PROCEDIMENTOS METODOLÓGICOS}

Na tentativa de preencher essa lacuna, lançamo-nos ao desafio de investigar a utilização do registro durante o processo pedagógico. Para tanto, o Caderno de Registros ${ }^{1}$ de um professor que afirma colocar em ação a perspectiva cultural da Educação Física na escola estadual em que atua com as turmas do ciclo inicial do ensino fundamental foi submetido à análise cultural. Trata-se de um arquivo eletrônico organizado cronologicamente entre março de 2015 e agosto de 2016. Contém fotos, vídeos, áudios e anotações referentes às atividades de ensino e às respostas dos estudantes, identificadas por meio de conversas (transcritas pelo próprio docente) e de desenhos que fizeram a pedido do docente.

A análise cultural foi a maneira escolhida para interpelar os registros. A escolha se faz pela contribuição que o método pode oferecer para o campo que esse trabalho se sustenta, os Estudos Culturais. Além do rompimento com o cânone que sempre esteve presente nas ciências positivistas, o deslocamento gerado por esse movimento teórico permite que a cultura seja analisada nos diferentes locais (NEVES, 2018). Segundo Wortmann (2002, p. 78), nessa proposta cabe "examinar um pouco mais detidamente as relações entre linguagens, representações, produções de significados (e) discursos".

A análise cultural não se resume em descrever o trabalho como um campo passivo traduzido em meros registros. Apoiado na noção de representação cultural de Hall (1997), tal procedimento permite analisar os diferentes circuitos de 
significação colocados em ação. Torna-se central o entendimento de como os significados e as práticas são construídos no discurso e como o poder e a linguagem regulam condutas e ajudam a construir representações produzindo diferentes sujeitos. Na visão de Wortman (2002), a preocupação da análise cultural é "penetrar nas linguagens" e "garimpar" os significados em uma multiplicidade de textos.

\title{
UMA ROTA, VÁRIOS CAMINHOS
}

\author{
O registro permite que vejamos a historicidade do proces- \\ so de construção dos conhecimentos, porque ilumina a histó- \\ ria vivida e auxilia a criação do novo a partir do velho. Oferece \\ segurança porque relembra as dificuldades anteriores e a sua \\ superação, dando coragem para enfrentar novos desafios e \\ dificuldades que, como as anteriores, poderão ser superadas. \\ (WARSCHAUER, 1993, p. 63)
}

Apesar da importância que a literatura educacional atribui ao registro do trabalho docente, não deixa de ser interessante constatar que o assunto não tem despertado a atenção da comunidade científica da Educação Física. Uma consulta aos principais bancos de dados disponíveis na internet, ${ }^{2}$ mediante a combinação dos descritores "registro" e "Educação Física”, localizou quatro trabalhos.

Piragibe (2006) analisou o processo de reflexão sobre a prática pedagógica durante um curso de formação continuada em Educação Física mediado pela técnica dos diários de classe. A pesquisadora debruçou-se sobre os registros reali-

2 SCIELO (Scientific

Electronic Library Online), Latindex (Sistema Regional de Información en Línea para Revistas Científicas de América Latina, el Caribe, España y Portugal) e Biblioteca de Teses e Dissertações da Coordenação de Aperfeiçoamento de Pessoal de Nivel Superior (Capes). zados pelas professoras, apontando a superficialidade com a qual as instituições de ensino lidam com a prática reflexiva, fazendo com que cada vez mais os estudantes sejam transformados em meros reprodutores das informações adquiridas. Após o ciclo de atividades formativas, a análise dos registros produzidos pelas professoras constatou mudanças na forma de pensar, agir e planejar as aulas.

Melo (2008) também investigou os registros das aulas de Educação Física. A sua análise dos portfólios elaborados pelos estudantes e do diário da professora corroboram a 
melhora da aprendizagem e a legitimação, por assim dizer, dos instrumentos de avaliação empregados pela docente. A pesquisadora define portfólio como a reunião das produções realizadas pelos alunos, alunas e docentes durante as aulas, em uma pasta ou em um arquivo de livre acesso e fácil consulta. Ou, ainda, uma forma de diário de bordo no qual o professor ou a professora realiza uma espécie de resumo sobre essas produções, inserindo-o no registro. Pode ser, também, um dossiê que tem por característica o arquivamento dos registros, respeitando a ordem cronológica em que esses acontecem.

O portfólio permite ao aluno representar a sistematização
do conhecimento de forma cumulativa e dinâmica, além
de atender aos desejos e necessidades de complementa-
cão de cada aluno. De um lado, a qualidade de ser um pro-
cesso cumulativo pressupõe a necessidade do professor
acompanhar os alunos em seus avanços, de outro, o fato
de ser dinâmico permite (e impõe) retomadas, idas e vin-
das sobre o que o aluno já sabe e aquilo que ainda não é
conhecido. Esse é o ponto mais especial do portfólio, que
favorece a formação de sujeitos autônomos e conscien-
tes de seus processos de aprendizagem, já que possibilita
ao aluno reconhecer e controlar a própria aprendizagem.
(MELO, 2008, p. 35)

O papel que as duas pesquisadoras atribuem ao registro é semelhante. Quer seja no formato de portfólio ou diário de classe, ambos contribuem para documentar o que foi socialmente construído com os alunos, aproveitando, dessa forma, toda e qualquer informação relevante ao processo vivenciado, mesmo que cada uma tenha seus próprios objetivos e proposições. Por entender que o processo pode ser longo e durar mais do que uma aula, faz-se necessário registrar as discussões realizadas para que, na aula seguinte, se dê continuidade a partir do ponto anterior.

Santos e Maximinano (2013) investigaram a forma como três professoras de Educação Física enxergam a avaliação no cenário escolar. Os autores constataram o teor fiscalizatório adotado pelas participantes do estudo, uma vez que, 
apoiadas nos registros elaborados pelos estudantes, revelaram preocupações com a apreensão dos conteúdos desenvolvidos durante as aulas. Os resultados sinalizam o entendimento que as professoras têm da prática avaliativa como uma forma de quantificar notas para as produções discentes ou, em certos casos, atribuir valores para a participação nas aulas.

Na perspectiva cultural da Educação Física, o registro tem sido visto ora com fim em si mesmo, ora para a avaliação após a finalização das tematizações propostas. O registro como recurso para a avaliação é encarado como um texto em constante construção, assim como toda a prática cultural, o que se distancia dos modelos avaliativos das propostas convencionais que excluem e classificam os alunos e alunas.

$\bigcirc$ registro atento das vivências, ressignificações, pesquisas, visitas, presença de membros da comunidade apresentados em fotos, filmagem, relatos, anotações, mudanças nas formas de realizar movimentos fornecem importantes informações ao professor, possibilitando-lhe avaliar o processo, permitindo-Ihe identificar insuficiências, limites, acertos e ganhos conquistados por meio das atividades de ensino, além de fornecerem informações que subsidiam possíveis modificações na prática pedagógica. (ESCUDERO, 2011, p. 101)

A pesquisa de Escudero (2011) é a que mais se aproxima do presente estudo. Embora reconheça a importância do registro como recurso para avaliação no currículo cultural da Educação Física, não lhe confere status de objeto de pesquisa, tampouco teceu considerações a respeito. A análise da transcrição das entrevistas e da documentação produzida pelos docentes que colocam em ação a proposta revela a noção de texto em construção, uma produção escrita baseada em informações sobre a ação educativa: produções dos alunos, pesquisas realizadas tanto pelos professores como pelos alunos e vivências corporais, distanciando-se do viés classificatório e excludente. Essa escrita se assemelha a uma estrutura provisória que, embora apresente desenhos diferentes, para organizá-la, os professores utilizaram recursos pedagógicos 
semelhantes, especificamente, às ações de mapear, registrar, pesquisar e decidir pela continuidade ou pela retomada das ações didáticas planejadas, entretecidas pelo diálogo.

A autora não deixa dúvidas de que a avaliação no currículo cultural da Educação Física se desprende da mera verificação das aprendizagens alcançadas pelos estudantes no final dos trabalhos. Por isso, é fundamental refletir com atenção a partir de suas vozes e silêncios. Sobre o assunto, Esteban (2003) já dissera que, estando aberto ao outro, o professor pode, apesar da surpresa, ou talvez como consequência dela, refletir sobre o que o seu aluno diz e sobre a avaliação que ele mesmo havia feito.

Escudero (2011) também envereda por esse caminho ao afirmar que, ao olharmos para um quadro pronto e acabado, temos uma visão clara do produto; contudo, nele o processo desaparece. $O$ processo também é valioso, e não somente $o$ produto. A questão que a pesquisadora deixa em aberto é como a avaliação no currículo cultural pode efetivamente levar em consideração todo o percurso, e não somente o seu resultado.

\section{ANÁLISE DA ROTA DOCENTE}

No início do ano letivo de 2015, o professor mapeou as brincadeiras da comunidade por meio de passeios a pé pelo bairro da escola e pediu às crianças que desenhassem aquelas que conheciam. Após a leitura das produções infantis, fez o primeiro registro.

3 Todos os nomes citados são fictícios.

FIGURA 1 - Desenho de Luisa ${ }^{3}$

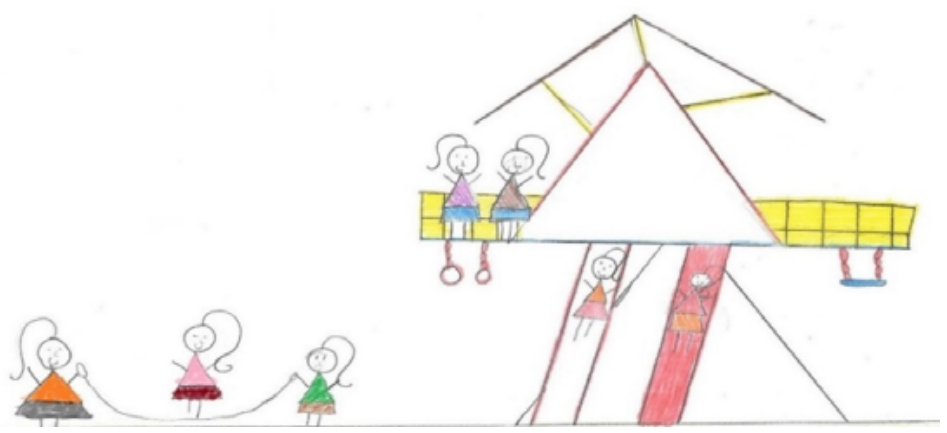




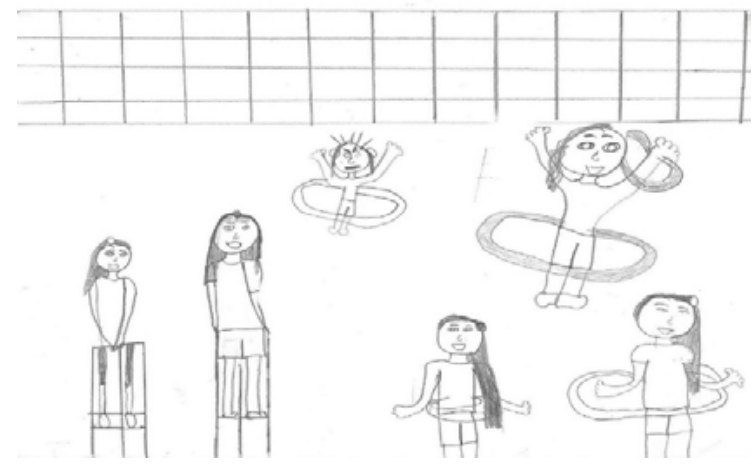

FIGURA 3 - Desenho de Paulo

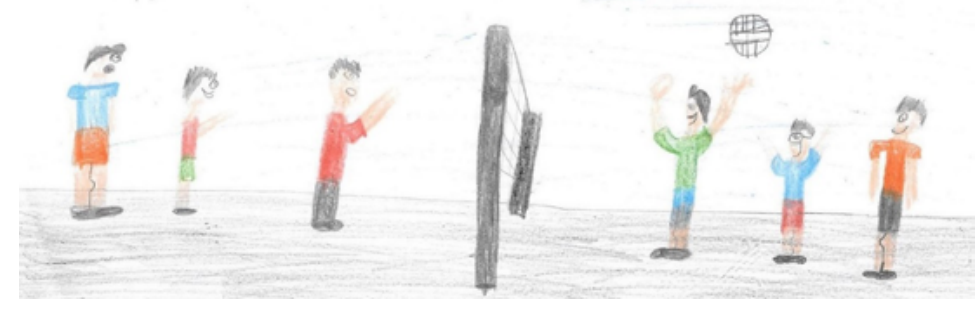

Solicitei que as crianças desenhassem o que compreendiam sobre as brincadeiras que faziam fora da escola. Algumas crianças perguntaram se podiam desenhar materiais também. Essa atividade tem o objetivo de verificar qual a representação que os estudantes carregam sobre as diferentes brincadeiras que conhecem. (Caderno de Registros, ${ }^{4}$ março de 2015)

Após analisar os desenhos de algumas crianças (figuras 1, 2 e 3), percebi que determinadas brincadeiras e determinados brinquedos fazem parte ao chamado universo feminino e masculino. Em vários momentos, percebo a distinção de gênero de acordo com a representação dos estudantes. (Caderno de Registros, março de 2015)

Reconhecendo as identidades culturais dos estudantes e observando distinções entre as brincadeiras retratadas pelos meninos e pelas meninas (eles desenharam esportes ou outras práticas vigorosas, enquanto elas preferiram brincadeiras mais contidas), o professor organizou diversas vivências
4 Caderno de Registros é o nome que o docente dá ao seu compilado de observações que proporciona as necessárias informações para que possa repensar sua prática pedagógica. 
nas aulas seguintes, disponibilizando materiais variados, a fim de analisar como as crianças se agrupariam e como escolheriam seus materiais.

Mesmo oferecendo uma grande quantidade de materiais, as crianças reforçaram a ideia de que certas práticas e certos materiais são permitidos a determinados grupos. Assim que pedi para que as crianças entrassem na quadra e pegassem o material que quisessem, as meninas entraram, pegaram cordas, bambolês e bolas de borracha e se dirigiram ao parque (que fica ao lado na quadra, no canto). Já os meninos, pegaram a bola de futebol e já foram jogar futebol na quadra. Nada combinado previamente. As crianças se agruparam e assumiram cada qual seus espaços como se fosse algo já determinado. (Caderno de Registros, março de 2015)

Os registros do professor corroboram a ideia de que os diferentes grupos sociais adquiriram, ao longo da história, permissões diferentes para atuar nos mais variados espaços e práticas disponíveis. A escola se oferece como ambiente propício à discussão democrática e à desconstrução de determinadas representações.

Desta forma, as relações de poder que atuam na cons-
trução de gênero devem ser amplamente debatidas no
cotidiano escolar, trazendo para a cena pedagógica as
diferentes formas de identificações que constituem uma
sociedade, potencializando e ressaltando as vozes das mi-
norias frente à avalanche discursiva que insiste em fabri-
car verdades únicas. (AGUIAR et al., 2016, p. 50)

A partir de suas observações e alinhando sua prática pedagógica aos princípios e orientações didáticas do currículo culturalmente orientado de Educação Física, o docente propôs, aos estudantes, atividades de ampliação, com vistas a oferecer-lhes informações oriundas de fontes diferentes. A turma se dirigiu à sala de informática da escola a fim de pesquisar sobre o tema.

Realizamos hoje uma pesquisa na sala de informática. A ideia era que as crianças pudessem ver que as brincadeiras que realizam aqui na escola muitas vezes também são realizadas em 
outros espaços, mesmo que, para isso, ela tenha que ser ressignificada de acordo com as necessidades do grupo que a realizará. (Caderno de Registros, abril de 2015)

As crianças identificaram muitas brincadeiras parecidas com aquelas que fazem na escola, mas algumas são bem diferentes. (Caderno de Registros, abril de 2015)

Professor: Quais as brincadeiras que vocês acharam que são parecidas com aquelas que fazemos aqui na aula de Educação Física?

Aline: Eu achei o "boca de forno". A única coisa que muda é o que o pegador fala e o que as crianças respondem [em seguida, a criança detalha a brincadeira realizada em Pernambuco - fonte da pesquisa - e a realizada em São Paulo pelos estudantes durante a aula de Educação Física].

Professor: Mais alguma brincadeira?

Marcos: Peão e pular corda. Só muda a música que canta, mas o resto é igual. (Caderno de Registros, abril de 2015)

Pesquisar com as crianças é uma forma de ampliar os conhecimentos acerca da prática corporal tematizada. Trata-se de uma atividade de ensino com potencial para fornecer argumentos necessários a uma análise crítica sobre os fatores que impulsionam as diferentes práticas nos diferentes espaços.

Se o que se pretende é formar cidadãos para uma atuação crítica, democrática e transformadora da sociedade, é preciso que os conhecimentos adquiridos através de atividades de ensino possibilitem leitura, interpretação e ação, não só no interior da escola mas também no interior no cotidiano das relações sociais. (NEIRA; NUNES, 2009, p. 34)

Uma prática pedagógica preocupada com a construção de uma sociedade menos desigual deve considerar outras representações advindas das mais variadas culturas. Considerando que as diferentes práticas e culturas transitam pela escola, podemos afirmar que, pelo menos sob o ponto de vista de acesso a um espaço outrora exclusivo a determinados grupos sociais, 
as situações didáticas organizadas pelo docente participante do estudo buscam inspiração na justiça curricular, ou seja, cumprem a função de incluir outras formas de representação das práticas corporais a fim de, quem sabe, desestabilizar a hegemonia desfrutada pelos esportes da tradição euro-estadunidense, quando comparada à condição das brincadeiras, danças e lutas produzidas e reproduzidas por outros povos.

Para valorizar as raízes culturais da comunidade na qual a escola está inserida, as manifestações corporais dos grupos de origem e pertencimento dos alunos transformam-se em temas de estudos (NEIRA, 2018). A tematização, mais do que dogmatizar conceitos, busca habitar os planos de imanência das práticas corporais, de modo a problematizar os acontecimentos para produzir novos conceitos que ajudem a enfrentar os problemas vivenciados pelos sujeitos (SANTOS, 2016).

Nessa esteira, o docente, ao tematizar o funk com as crianças, propôs a análise das representações que cercam a dança, desde o discurso das crianças até a forma como é tratada pelas grandes mídias.

FIGURA 4 - Foto da lousa com registros dos tipos de funk que as crianças conheciam

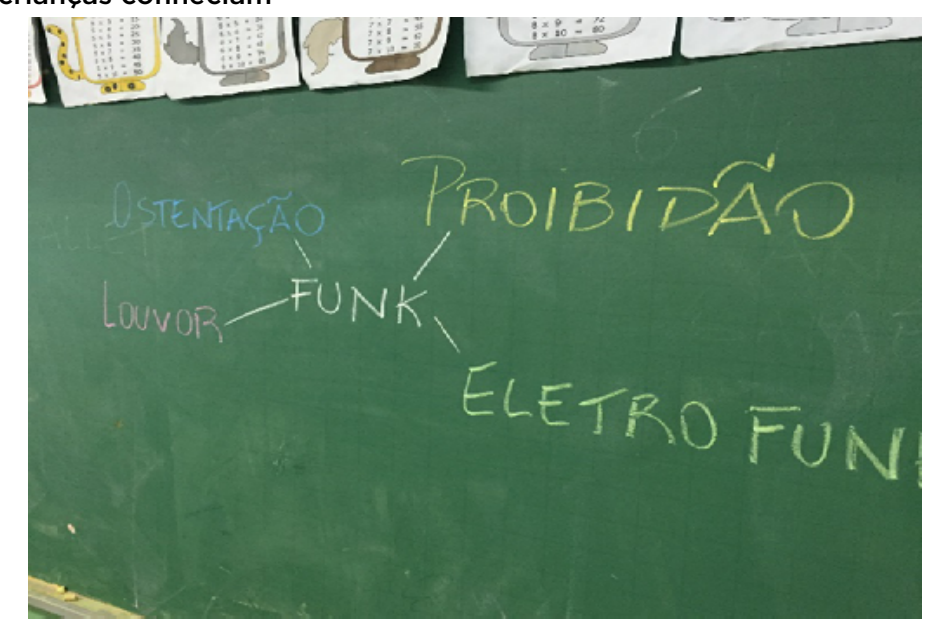


FIGURA 5 - Crianças registrando os conhecimentos sobre o funk

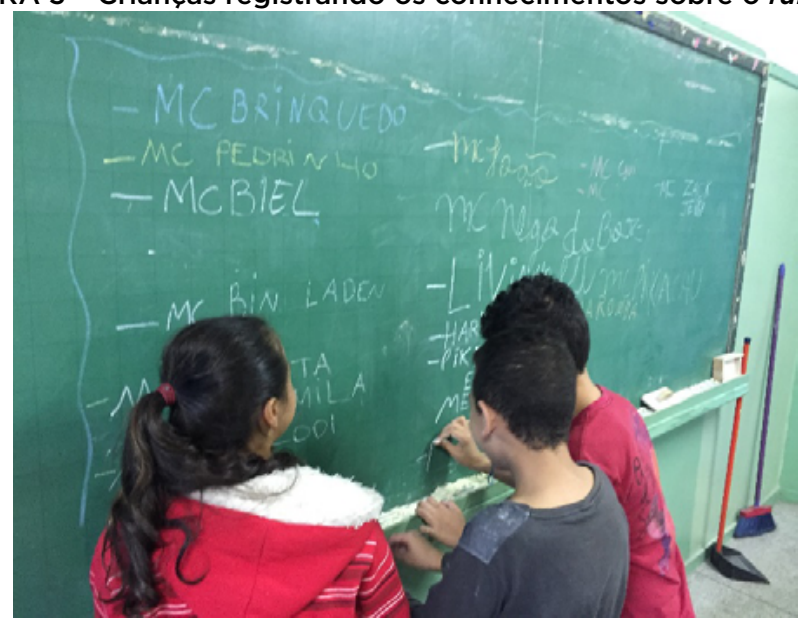

A partir das informações coletadas durante a aula (figuras 4 e 5), podemos elencar os MCs que as crianças conhecem bem como quais elas gostam de ouvir. Para a próxima aula, vou baixar as músicas para que façamos uma vivência das coreografias que conhecem. (Caderno de Registros, junho de 2016)

As anotações realizadas pelo docente, a partir dos acontecimentos de aula, permitem que as ações didáticas sejam constantemente reorganizadas, a fim de proporcionar, aos estudantes, oportunidades para que suas representações sejam colocadas em evidência, dando lugar - ou não - a outras formas de significar as coisas do mundo. Isso posto, as vivências assumem um papel fundamental para que os estudantes percebam que as diferentes práticas corporais assumem significados distintos de acordo com seu contexto de ocorrência. Trata-se de levar em consideração a ancoragem social dos conhecimentos.

Um artefato construído na cultura como as manifestações da cultura corporal não tem sentido em si. Sua existência se deve ao processo de significação pelo qual passou e que instaurou aquilo que ele é. Uma dança, uma luta ou esporte tem sentido para o grupo que o formulou e nele se expressam intenções, histórias, relações e sentidos. (NEIRA; NUNES, 2009, p. 11). 


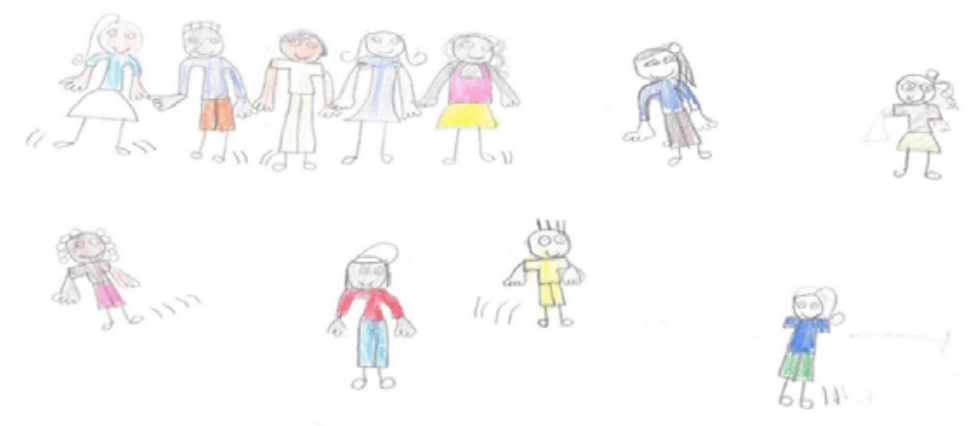

Hoje fizemos as vivências do funk. Cada grupo escolheu uma música e passou a coreografia para os demais alunos da sala. No final da aula, pedi para que desenhassem aquilo de mais significativo que tinham feito. (Caderno de Registros, junho de 2016)

Os desenhos e fotografias evidenciam a importância do registro na ação didática culturalmente orientada, afinal, foi a partir deles que o professor comparou situações vividas em momentos diferentes. Essa comparação, que reconhecemos como uma prática avaliativa, municia o docente para problematizações que advirão. Denominamos esse processo de reorientação das rotas, em alusão ao traçado imprevisível que a aula de Educação Física assume quando as vozes dos estudantes são tomadas com seriedade no desenrolar dos trabalhos. Nesse sentido, corroborando a noção de escrita-currículo desenvolvida por Bonetto (2016), qualquer tipo de previsibilidade e planejamento que engesse a prática docente e a trajetória didática cria obstáculos ao processo pedagógico. Isso denota que a prática avaliativa precisa mudar seu enfoque, deixando de enquadrar o estudante em números, metas e objetivos a serem alcançados. A fim de alertar sobre os riscos que uma perspectiva estruturada oferece, Esteban (2010) afirma que um projeto hegemônico e unívoco de escola não atende às múltiplas demandas de uma sociedade marcada pela diferença cultural, tampouco acolhe os sujeitos que a compõem.

Aqui não se está afirmando a eliminação da avaliação, mesmo porque concordamos com Oliveira e Pacheco (2013) 
quando ressaltam que a avaliação é parte integrante do currículo na medida em que a ele se incorpora como uma das etapas do processo pedagógico.

As avaliações - como os currículos, as metodologias, os

calendários e outras coisas do processo educativo - podem ser tecidas - construídas - a partir das relações de comunicação que fazem parte do cotidiano escolar, com respeito à diversidade e às especificidades, frutos das negociações que as relações dialogais propiciam. (RIBETTO et al., 2013, p. 110)

A análise do material produzido pelo docente revela que o registro, enquanto orientação didática que caracteriza a perspectiva cultural da Educação Física, é um recurso importante para, segundo Neira (2018), evitar o daltonismo cultural e disponibilizar outros olhares, sob outros ângulos, incentivando, assim, uma ação mais solidária com os conhecimentos que circulam na sociedade. Isso fica visível nas ações do professor. A todo momento sua preocupação é ouvir os diferentes posicionamentos dos estudantes para que, na aula seguinte, possa chegar preparado para problematizar determinadas questões não pensadas anteriormente, contribuindo para que as crianças ampliem suas representações sobre as práticas corporais e seus representantes.

FIGURA 7 - Desenho de Jânio

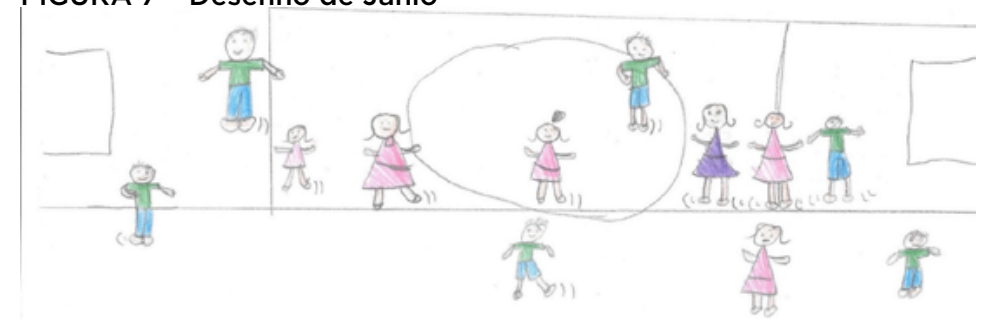




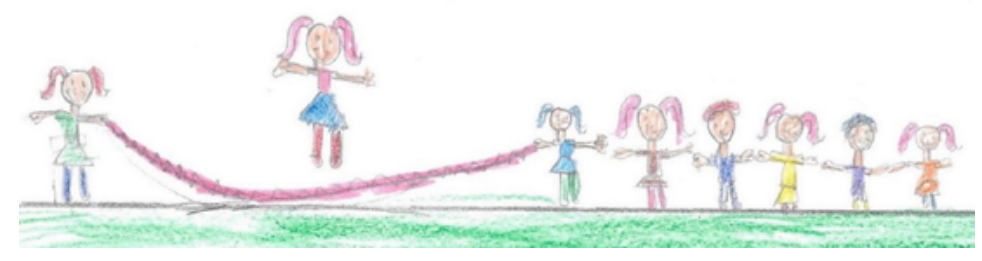

FIGURA 9 - Desenho de Vanessa

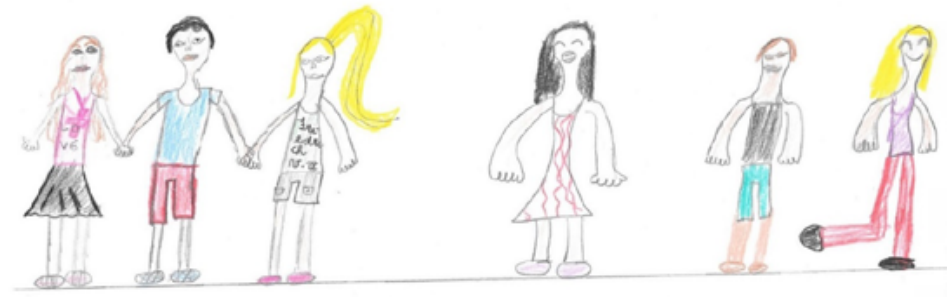

Os desenhos de Jânio (Figura 7) e Paula (Figura 8) foram feitos ao final da tematização das brincadeiras. Durante o mapeamento no início do ano, a turma havia dito que pular corda era uma brincadeira tipicamente das meninas. Após todas as propostas trazidas para as crianças durante as aulas de Educação Física, pedi para que elas desenhassem os momentos mais significativos. Diferente do que aconteceu no início do ano, as crianças desenharam meninos e meninas brincando juntos. (Caderno de Registro, novembro de 2015)

Em relação ao desenho de Vanessa (Figura 9), podemos estabelecer algumas reflexões. Quando iniciamos com a tematização do funk nas aulas de Educação Física, algumas crianças (e a própria Vanessa) disseram que se tratava de uma dança proibida para crianças porque expunha o corpo, que os pais proibiam eles e elas de escutarem funk e que os MCs se vestiam mal. As crianças chegaram a usar as palavras "vagabundo", "malandro" $e$ "marginal" para designar os/as cantores/as e dançarinos/as de funk. Após todas as problematizações propostas durante os trabalhos, algumas crianças mudaram de opinião. (Caderno de Registro, novembro de 2015) 
Os registros do docente sinalizam a abrangência do currículo cultural nas aulas de Educação Física, reforçando a importância de se incluir, no bojo das análises, as experiências dos estudantes angariadas além dos muros escolares.

A divisão dos espaços durante algumas atividades realizadas nas aulas de Educação Física vai ao encontro daquilo que observei no mapeamento. Caminhando pelo bairro, as únicas duas praças disponíveis são totalmente utilizadas pelos meninos. Não vi nenhuma menina nem em volta desses espaços. Em uma das praças tem um playground onde meninos e meninas, acompanhados de suas mães, brincam. (Caderno de Registros, agosto de 2015)

Apoiados nesse trecho, podemos afirmar que, no espaço observado pelo professor, algumas brincadeiras são legitimadas como uma prática comum entre meninos e meninas. Porém, no caso de alguns esportes, como o futebol, ele se torna masculinizado. Faz-se, portanto, fundamental, a presença dessas práticas corporais na escola, para que essas questões sejam investigadas e problematizadas com os estudantes.

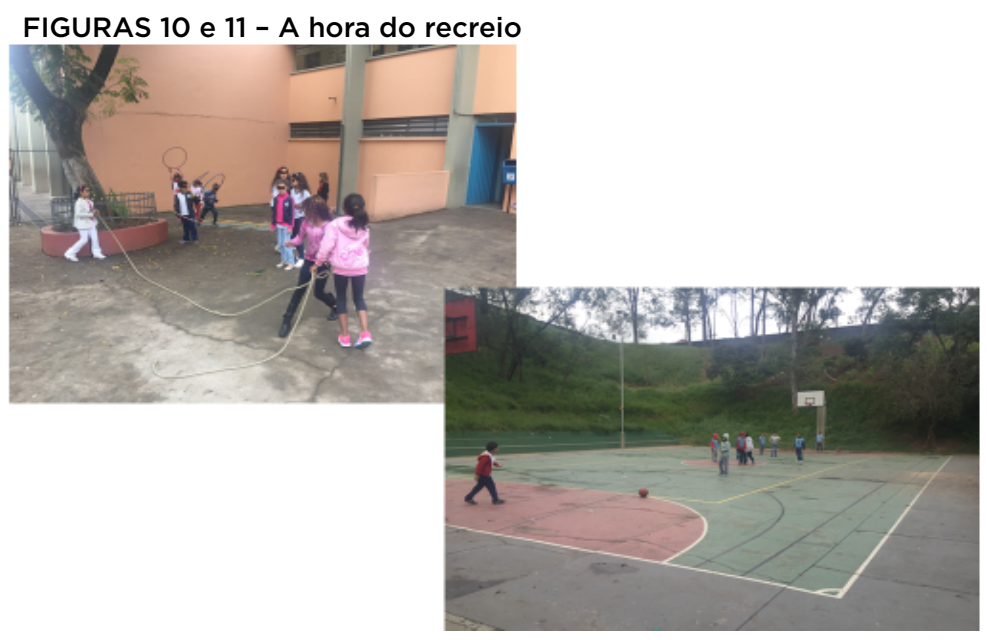

As fotos (figuras 10 e 11) me deixaram preocupado em relação ao desenvolvimento de um trabalho culturalmente orientado. Será que está sendo realizado com qualidade? Será que está correto? Será que as crianças percebem que os espaços 
5 Tia X é o nome dado à agente de organização escolar responsável por acompanhar as crianças durante 0 intervalo. pertencem a todos e a todas? Será que essa foto foi um recorte isolado, sem relevância? Ou será que, a partir de seus interesses (futebol, corda, bambolê), as crianças revelam o que realmente pensam, legitimando quem pode e quem não pode brincar? (Caderno de Registros, outubro de 2015)

A partir da reflexão do professor, lembramos que o mundo não foi apresentado aos estudantes na ou pela escola. Muito pelo contrário, antes de ingressarem no ambiente escolar, as crianças experimentaram situações profundamente marcadas pelas relações de gênero. Nota-se facilmente que os marcadores sociais perpassam as práticas corporais e, por essa razão, descontruir certas representações circundantes mediante atividades de aprofundamento torna-se um dos objetivos da Educação Física culturalmente orientada.

Após pesquisarmos sobre o rap em sites (relacionando o rap com os movimentos negros e o hip-hop), e de assistirmos a algumas batalhas de rimas postadas no YouTube, problematizamos as questões relacionadas às roupas dos rappers.

Dayane: Se um rapper entrar na escola, tomo mundo vai saber que ele é rapper, por causa das roupas, das correntes, do boné. Marcelo: É da hora. As roupas que os caras usam.

Fernanda: As meninas usam roupas da hora também.

Lucas: Mas as roupas é que são diferentes. As correntes nem todo rapper usa. Tem rapper que não tem corrente. 0 que vale é cantar e rimar.

Melissa: A gente faz batalha de rima na escola. A tia $X^{5}$ não gosta que a gente faça.

Professor: E por que ela não gosta disso?

Melissa: Sei lá.

Gisele: Ela fala que isso não é coisa de menina. Que tem palavrão e é feio.

Professor: Mas no rap tem palavrão?

Henrique: Às vezes tem. Depende da letra.

Igor: Mas não é nada pesado. É palavrão leve.

Professor: Mas quando vocês fazem as batalhas, vocês falam palavrão?

Caio: Não. 
Kaique: A tia está sempre perto da gente. Ela sabe que a gente não fala palavrão. É que ela não gosta de rap. Ela ouve música evangélica.

Isadora: É louvor que fala.

Kaique: É, isso aí.

Professor: Isadora, você também canta; é cantar que se fala quando se fala em louvor?

Isadora: Ahã. Está certo. E eu vou no culto todo domingo com meus pais. A tia $X$ frequenta a minha igreja.

Mayky: Por isso que você é chata também.

Professor: Pessoal, espera um pouco. Estamos conversando numa boa. Não tem necessidade disso, né, Mayky?

Mayky: Mal aí.

Isadora: Então, professor, como eu estava falando, a tia frequenta a minha igreja, mas não tem nada a ver isso que o Mayky falou. Eu, se quiser, ouço qualquer música.

Beatriz: É verdade. Ela até já ficou com a gente nas batalhas. Luis Victor: É que tem gente que não gosta e acabou. Fazer o quê? Cada um tem um gosto.

Robert: Professor, você disse que a gente ia fazer uma dança. Quando vai ser?

Professor: Boa, Robert. Na próxima aula, em grupos, vocês vão compor uma coreografia inspirada no rap que assistimos hoje. Ensaiem durante a aula e, no final, cada grupo apresenta a sua dança. Agora façam os grupos e decidam qual música querem dançar. Podem deixar que o som eu pego para a próxima aula. (Caderno de Registros, junho de 2016)

Hoje a aula foi toda voltada para a ressignificação das danças que as crianças tinham assistido na última aula. Na primeira aula, formei grupos, com seis a oito integrantes. Cada grupo deveria elaborar uma coreografia e ensaiar. Na aula seguinte os grupos apresentaram suas coreografias. Um a um, todos os grupos se posicionaram à frente dos demais para a apresentação. Eu fiquei responsável em acionar a música. (Caderno de Registros, setembro de 2014)

Interessante que as crianças criaram grupos mistos. Não houve qualquer orientação nesse sentido. Deixei que ficassem à 
vontade. Talvez o fato de algumas meninas e meninos ficarem juntos durante o recreio para fazerem a batalha das rimas tenha influenciado na formação dos grupos. Mas como não puderam formar um único grupo, tiveram que desmembrar a "turma da batalha de rima" e, dessa forma, a sala ficou com uma divisão mista e homogênea. (Caderno de Registros, setembro de 2015)

FIGURA 12 - Desenho de Isadora

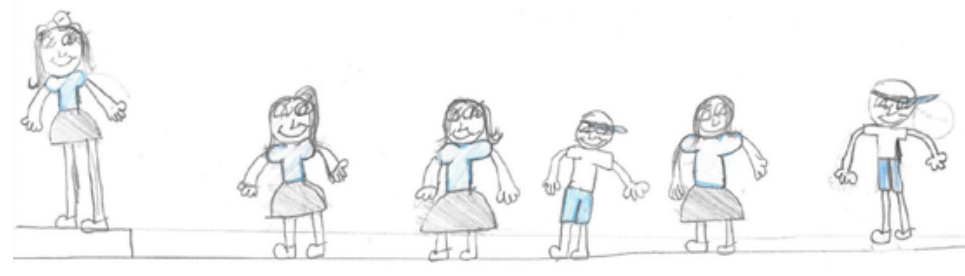

0 desenho (Figura 12) mostra as crianças dançando o rap. Destaquei o desenho da Isadora porque, na aula em que conversamos sobre as batalhas de rimas, ela disse que a agente de organização escolar frequentava a mesma igreja que ela e que não gostava dessas músicas. Ao que parece, pelo menos a partir do desenho, e também da fala da Isadora, para ela, isso não é um problema. (Caderno de Registros, setembro de 2015)

As crianças colocaram em seus desenhos alguns traços que para elas são bem característicos das pessoas que dançam e ouvem o rap. As calças folgadas e os bonés são bem evidentes. Lembrando que isso foi o tema de uma de nossas aulas, antes das ressignificações, quando fomos à sala de informática da escola para pesquisar em sites sobre o histórico do rap, os movimentos que influenciaram as danças e o conceito político de resistência, principalmente a partir do movimento black. As crianças puderam ver alguns rappers famosos, trechos de seus shows. Em um dos

6 Famoso rapper norte-americano, considerado uma das figuras mais expressivas do rap atual. vídeos, viram o 50 Cent $^{6}$ realizando uma batalha de rimas em uma de suas apresentações, em que ele escolhia duas pessoas da plateia, aleatoriamente. (Caderno de Registros, setembro de 2015)

No registro do professor, existe uma grande expectativa sobre o material que as crianças produziram após as atividades de ampliação e aprofundamento. É fundamental que se 
tenha expectativa sobre toda e qualquer ação pedagógica, mas o fato de os estudantes responderem de uma forma diferente daquela aguardada não descartaria o trabalho realizado. Muito pelo contrário, fortaleceria a importância dos registros docentes para que, cada vez com mais frequência, as atividades passem por um processo de reorganização, sempre em vista do tema estudado. Se o docente realiza diferentes formas de registros para essa reorientação, precisa que as crianças produzam materiais que lhe permitam uma análise mais próxima das representações infantis. Enveredando por esse caminho, é muito importante que os discentes não estejam influenciados ou contaminados por certos discursos no momento de seus registros. Em outras palavras, faz-se necessário que alunos e alunas tenham segurança para expor suas opiniões, dando vazão aos significados que atribuem às práticas corporais.

\section{REORIENTANDO A ROTA}

Mesmo se tratando de um importante recurso utilizado para reflexão sobre a prática pedagógica, causa estranheza a carência de estudos sobre registros de professores de Educação Física. Exceção feita ao trabalho de Escudero (2011), os demais que pudemos localizar deram a entender que seu emprego ocorre principalmente no momento de avaliar as aprendizagens dos estudantes.

As análises dos materiais produzidos pelo professor permitiram-nos compreender a importância do registro no planejamento das ações didáticas a partir dos acontecimentos de cada aula. Por conseguinte, os planos de ação cristalizados e previamente modelados no início do período letivo (ano, semestre ou bimestre), pautados nas expectativas que os docentes têm em relação ao ensino e à aprendizagem dos estudantes, cedem espaço às ações construídas democraticamente junto com os alunos, fundadas em cada problematização, fala, silêncio, desenho, conversa ou vivência.

A partir da análise do Caderno de Registros do professor que se disponibilizou a participar do estudo, constatamos que a forma como lida com o material se assemelha à 
7 Waze é um GPS gratuito em que os próprios usuários alimentam o programa com informações em tempo real dos acontecimentos relacionados ao trânsito. sinalização do GPS Waze ${ }^{7}$ em uma estrada, ou seja, oferece orientações sobre o caminho a seguir. A metáfora utilizada por ele próprio cai como uma luva. Não há como negar que os registros exercem um papel preponderante na avaliação da rota percorrida pelo professor e seus alunos.

Os resultados do presente estudo evidenciam que as ações didáticas futuras são pensadas a partir dos acontecimentos presentes; por essa razão, no currículo cultural da Educação Física, é impossível planejar sem a contribuição das vozes discentes. Logo, quanto mais ricos forem os registros e a análise, rotas mais seguras poderão ser traçadas.

Na visão de Padilha (2008), planejar é estabelecer caminhos que norteiem mais apropriadamente a execução da ação educativa. E essa "melhor execução" só é possível a partir do momento em que o docente incorpora em sua prática a realização de registros que permitam analisar o que ocorreu nas aulas, avaliando de que maneira as orientações futuras podem ser realizadas. Enveredando por esse caminho, não se pode pensar em uma prática docente enrijecida. Ela é avaliada, reinventada e reconstruída cotidianamente.

Ao propor uma forma de conceber a ação avaliativa a partir dos registros, o presente estudo extrapola as recomendações de Escudero (2011, p. 106), para quem a avaliação "é entendida como um texto em construção, como uma produção realizada por alunos e professores”. Além disso, complementa o trabalho de Bonetto (2016), pois ressalta a importância dos registros como dispositivos imprescindíveis à escrita-currículo.

Dessa maneira, concluímos que a perspectiva cultural do componente dá novos contornos à prática avaliativa. Os antigos preceitos de verificação e classificação podem ser substituídos pela avaliação do percurso, tendo em vista os objetivos traçados para cada tematização. A análise das ações didáticas observadas e da documentação pedagógica acumulada aponta que o registro docente é fundamental para que a rota inicialmente traçada possa ser reorientada a qualquer tempo. 


\section{REFERÊNCIAS}

AGUIAR, A. P. D.; MÜLLER, A.; NUNES, H. C. B.; LIMA, M. F. Relações de gênero na prática do futebol. In: NEIRA, M. G.; NUNES, M. L. F. (Org.). Educação física cultural: escritas sobre a prática. São Paulo: CRV, 2016. p. 165-180.

BONETTO, P. X. R. A "escrita-currículo" da perspectiva cultural de educação física: entre aproximações, diferenciações, laissez-faire e fórmula. 2016. Dissertação (Mestrado em Educação) - Universidade de São Paulo, Faculdade de Educação, São Paulo, 2016.

CANDAU, V. M. Multiculturalismo e educação: desafios para a prática pedagógica. In: MOREIRA, A. F.; CANDAU, V. M. Multiculturalismo: diferenças e práticas pedagógicas. 2. ed. Petrópolis: Vozes, 2008. p. 13-37.

ESCUDERO, N. T. G. Avaliação da aprendizagem da educação física na perspectiva cultural: uma escrita autopoiética. 2011. Dissertação (Mestrado em Educação) - Universidade de São Paulo, Faculdade de Educação, São Paulo, 2011.

ESTEBAN, M. T. A avaliação no cotidiano escolar. In: ESTEBAN, M. T. (Org.). Avaliação: uma prática em busca de novos sentidos. Rio de Janeiro: DP\&A, 2003. p. 7-28.

ESTEBAN, M. T. Diferença, aprendizagens e avaliação: perspectiva pós-colonial e escolarização. In: ESTEBAN, M. T.; AFONSO, A. F. (Org.). Olhares e interfaces: reflexões críticas sobre a avaliação. São Paulo: Cortez, 2010. p. 45-70.

HALL, S. A centralidade da cultura: notas sobre as revoluções culturais do nosso tempo. Educação e Realidade, Porto Alegre, v. 22, n. 2, p. 15-46, jul./dez. 1997.

MELO, L. F. 0 portfólio como uma possibilidade de intervenção pedagógica em educação física. 2008. Dissertação (Mestrado em Educação Física) Universidade de São Paulo, Escola de Educação Física e Esportes, São Paulo, 2008.

MÜLLER, A. A avaliação no currículo cultural de educação física: o papel do registro na reorientação das rotas. 2016. Dissertação (Mestrado em Educação) - Universidade de São Paulo, Faculdade de Educação, São Paulo, SP, 2016.

NEIRA, M. G. Educação Física. São Paulo: Blucher, 2011.

NEIRA, M. G. Educação física cultural: inspiração e prática pedagógica. Jundiaí: Paco Editorial, 2018.

NEIRA, M. G.; NUNES, M. L. F. Educação física, currículo e cultura. São Paulo: Phorte, 2009.

NEVES, M. R. O currículo cultural da Educação Física em ação: efeitos nas representações culturais dos estudantes sobre as práticas corporais e seus representantes. 2018. Dissertação (Mestrado em Educação) - Universidade de São Paulo, Faculdade de Educação, São Paulo, 2018.

OLIVEIRA, I. B.; PACHECO, D. C. Avaliação e currículo no cotidiano escolar. In: ESTEBAN, M. T. Escola, currículo e avaliação. São Paulo: Cortez, 2013.

p. 119-136. 
PADILHA, P. R. Planejamento dialógico: como construir o projeto políticopedagógico da escola. São Paulo: Cortez, 2008.

PIRAGIBE, V. Formação continuada em educação física para professores de educação infantil: a técnica do diário de aula. 2006. Dissertação (Mestrado em Educação Física) - Universidade de São Paulo, Escola de Educação Física e Esportes, São Paulo, 2006.

RIBETTO, A.; VASCONCELOS, G. A. N.; SGARBI, P.; FILÉ, V. Conversas sobre avaliação e comunicação. In: ESTEBAN, M. T. (Org.). Escola, currículo e avaliação. São Paulo: Cortez, 2013. p. 101-118.

SANTOS, I. L. A tematização e a problematização no currículo cultural de educação física. 2016. Tese (Doutorado em Educação) - Universidade de São Paulo, Faculdade de Educação, São Paulo, 2016.

SANTOS, W.; MAXIMIANO, F. L. Avaliação na educação física escolar: singularidades e diferenciações de um componente curricular. Revista Brasileira de Ciências do Esporte, Florianópolis, v. 35, n. 4, p. 883-896, out.|dez. 2013.

WARSCHAUER, C. A roda e o registro: uma parceria entre professor, alunos e conhecimento. São Paulo: Paz e Terra, 1993.

WORTMAN, M. L. Análises culturais - um modo de lidar com histórias que interessam à educação. In: COSTA, M. V. (Org.). Caminhos investigativos II: outros modos de pensar e fazer pesquisa em educação. Rio de Janeiro: Lamparina, 2002. p. 71-90.

Recebido em: 18 OUTUBRO 2017

Aprovado para publicação em: 10 SETEMBRO 2018 
